\title{
Molecular and Classical identification of Staphylococcus aureus, Isolated from Iraqi Patients with Recurrent Tonsillitis
}

\author{
Hawraa Fadhil ${ }^{1}$, Bushra Jasim Mohammed ${ }^{1}$ \\ ${ }^{1}$ Scholar Researcher, Institute of Genetic Engineering and Biotechnology, University of Baghdad, Iraq
}

\begin{abstract}
Tonsillitis is an infection of the tonsils caused by one of several types of bacteria or viruses. Staphylococcus aureus are one of most common bacteria isolated from recurrent tonsillitis, its identification by classical methods takes 3-5 days as well as the accuracy does not reach an absolute degree. So current study aimed to diagnose $S$. aureus by classical and molecular diagnosis to increase the accuracy of the diagnosis. Two hundred and fifteen tonsil swabs were collected from Iraqi patients susceptible suffered from recurrent tonsillitis who attended clinics in major hospitals in Najafe/ Iraq. Classical diagnoses of $S$. aureus were done by bacterial cultures, biochemical test and Vitek system. While molecular diagnosis achieved via PCR technique The results of classical methods showed that 50 isolates recovered from (195) suspected patients were $S$. aureus, while molecular diagnoses showed that 45 isolates out of 50 diagnostic $S$. aureus via classical methods were $S$. aureus with significant difference $(\mathrm{P} \leq 0.01)$. In conclusion, Molecular method is more sensitive in diagnoses of $S$. aureus than conventional testes in case of recurrent tonsillitis.
\end{abstract}

Key words: Classical diagnosis, Molecular diagnosis, PCR, S. aureus, Recurrent tonsillitis, Essential genes.

\section{Introduction}

Tonsillitis is an inflammatory condition of the tonsils due to bacteria, respiratory viruses, allergies or respiratory problems. Staphylococcus aureus is one of the most frequent pathogens in the etiology of recurrent tonsillitis and its relevance is due to its antimicrobial resistance and persistence in the internal tissues of the tonsils. Presence of the beta-lactamase producing Staphylococcus in tonsils microbiota can promote penicillin resistance. Staphylococcus aureus tonsillitis diagnosed mainly by history and clinical examinations. Superficial tonsillar swabs are often used as a guide in identifying the offending organism and the proper selection of therapy in recurrent tonsillitis ${ }^{[1]}$. Because appropriate treatment for tonsillitis depends on the cause, it's important to get a prompt and accurate diagnosis. Diagnosis is by either classical examinations as morphological characteristics of gram staining, and culture on media including: blood agar, Mannitol agar, as well as conventional and automated biochemical tests such catalase, coagulase, oxidize and VITEK2 system, additional to molecular diagnosis. Since culturing the bacterium can be difficult, so molecular test is the most accurate. Classical methods are laborious and time consuming taking 3-5 days ${ }^{[2]}$. The PCR has proven to be an indispensable tool for detection of infectious agents in the laboratory. Essential genes are those genes of an organism that are thought to be critical for its survival. The use of $16 \mathrm{~S}$ rRNA gene sequences to study bacterial phylogeny and taxonomy has been by far the most common housekeeping genetic marker used for a number of reasons, included its presence in almost all bacteria, often existing as a multigene family, or operons; the function of the $16 \mathrm{~S}$ rRNA gene over time has not changed, suggesting 
that random sequence changes are a more accurate measure of time (evolution); and the 16S rRNA gene is large enough for informatics purposes ${ }^{[3]}$. The fem A gene is occurring naturally in $S$ aureus, which is essential for the expression of high-level methicillin resistance ${ }^{[4]}$. Therefore, in the present study, we tried to diagnose $S$. aureus with methicillin resistant from recurrent tonsillitis which isolated from Iraqi patients depending on these essential genes by molecular and classical methods.

\section{Subjects, Materials and Methods}

\section{Subjects}

Tonsil swabs were collected from (215) patients with recurrent tonsillitis episodes for at least one year, characterized by sore throat or swollen painful tonsils with fever or symptoms of systemic illness, who attended the clinics in major Hospitals in najafe city; AL-Sader Teaching Hospital, al-hakeem, alsajad Hospital and Center of Public Healthy, from the beginning of October/ 2019 to the end of February / 2020, the age of patients was ranged between (2$60)$ years with mean age (31) years for both sexes, and (50) samples from apparently healthy persons as a control group.

\section{Classical diagnoses methods}

Samples were directly inoculated from transport media, on the blood agar and mannitol salt agar at $37^{\circ} \mathrm{C}$ for $18-24$ hours. After incubation, the isolated colonies were identified by morphological feature, and biochemical tests according to Atlas et al ${ }^{[5]}$. Single colony of the isolated bacteria was used for direct examination by wet mounted film and gram stained for detection of bacteria. A progression of biochemical tests was performed as catalase, oxidase, coagulase and Vitek 2 test. The antimicrobial susceptibility test had been done by disc diffusion method according to Kirby-Bauer disc diffusion method.

\section{Estimation of the DNA concentration and} purity

Concentration and purity of the DNA were carried out according to Sambrook and Russell [6], by using Nanodrop (BioNeer /Korea).

\section{Molecular diagnoses methods}

Genomic DNA extraction form bacterial cells using Gram-Positive Bacteria protocol by genomic DNA purification kit (Bioneer/ Korea). according to Sambrook and Russell ${ }^{[6]}$.

Amplification of essential gene regions by PCR Conventional

Amplification of essential gene regions (16S RNA and femA) by PCR was done by using tow types of specific primers pairs (Table 1) which supplied by Alpha/ Canada, first type for $16 \operatorname{SrRNA}$ gene to identification staphylococcus spp., while the second type for the detection femA gene which confirm virulence factor according to Al-musawi et al. ${ }^{[7]}$.

Table 1: Sequences and sizes of $16 S R N A$ and $f e m A$ gene primers.

\begin{tabular}{|c|c|c|c|c|c|}
\hline $\begin{array}{c}\text { Target } \\
\text { gene }\end{array}$ & & Sequence (5'-3') & $\begin{array}{c}\text { Tm } \\
\left({ }^{\circ} \mathbf{C}\right)\end{array}$ & $\begin{array}{c}\text { Product } \\
\text { size }\end{array}$ & Reference \\
\hline \multirow{2}{*}{ 16S RNA } & F & 5'-GGTCTTGCTGTCACTTATAGATGG-3' & \multirow{2}{*}{60} & $164 \mathrm{bp}$ & \multicolumn{1}{c|}{$\begin{array}{c}\text { Al-musawi et } \\
\text { al., (2014) }\end{array}$} \\
\cline { 2 - 4 } femA & R & 5'-CGGAAGATTCCCTACTGCTG-3' & \multirow{2}{*}{60} & $647 \mathrm{bp}$ & \\
\cline { 2 - 5 } & $\mathrm{R}$ & 5'-AACAGCTAAAGAGTTTGGTGCC-3' & 5'-CATCACGATCAGCAAAAGCT-3' & \\
\hline
\end{tabular}


The PCR program carried out according to Sagaidak et al. ${ }^{[8]}$ and (Barzani et al ${ }^{[9]}$ for $16 \operatorname{SrRNA}$ and femA genes as clarified in tables (2). Three microliters of PCR products were separated on $2 \%$ agarose gel with DNA dye is RedSafe (Intron/ Korea) and a ladder (100bp) (Promega/USA) as visualized in figure (1).

Table.2: PCR program that apply in the thermo-cycler

\begin{tabular}{|c|c|c|c|c|c|c|}
\hline gene & $\begin{array}{c}\text { Initial } \\
\text { denaturation }\end{array}$ & denaturation & Annealing & Extension & Final xtention & Cycle \\
\hline 16 SrRNA & $94{ }^{\circ} \mathrm{C}$ for $5 \mathrm{~min}$ & $94^{\circ} \mathrm{C}$ for $30 \mathrm{sec}$ & $56{ }^{\circ} \mathrm{C}$ for $30 \mathrm{sec}$ & 72 for $1 \mathrm{~min}$ & 72 for $5 \mathrm{~min}$ & 35 \\
\hline femA & $95{ }^{\circ} \mathrm{C}$ for $5 \mathrm{~min}$ & $94{ }^{\circ} \mathrm{C}$ for $1 \mathrm{~min}$ & 60 for $1: 30 \mathrm{~min}$ & 72 for $2 \mathrm{~min}$ & 72 for 7 min & 35 \\
\hline
\end{tabular}

\section{Results Analysis}

The Statistical Analysis System- SAS ${ }^{[10]}$ program was used to detect the effect of difference factors in study parameters. Least significant difference -LSD test (Analysis of Variation-ANOVA) was used to compare between means and Chi-square test which was used to compare between percentage ( 0.05 and 0.01 probability).

\section{Results}

Tonsil swabs of patients suffered from recurrent tonsillitis; bacteria were examined microbiologically. The result showed that 195 (90.69\%) samples were positive for bacterial growth recovered from (215), the rest samples $20(9.30 \%)$ showed no bacterial growth, that's me be due to tonsils can be caused by viruses, fungi, and allergy ${ }^{[16]}$. On the other hand, 50 (25.64\%) samples were positive for $S$. auerus which was the most prevalent pathogen, while 145(74.36) samples were (Streptococcus pyogenes, Pseudomonas aeruginosa and Klebsiella pneumoniae formed the remainder percentageas. Colonies of $S$. aureus were observed after an incubation period of (18-24) hours on blood agar plates, appeared yellow-gray, round, smooth, raised, and some colonies surrounded by a halo or clear zone of $\beta$ - haemolysis as shown in figure (2), which confirmed the diagnosis as $S$. aureus according to Leboffe and Pierce ${ }^{[11]}$.

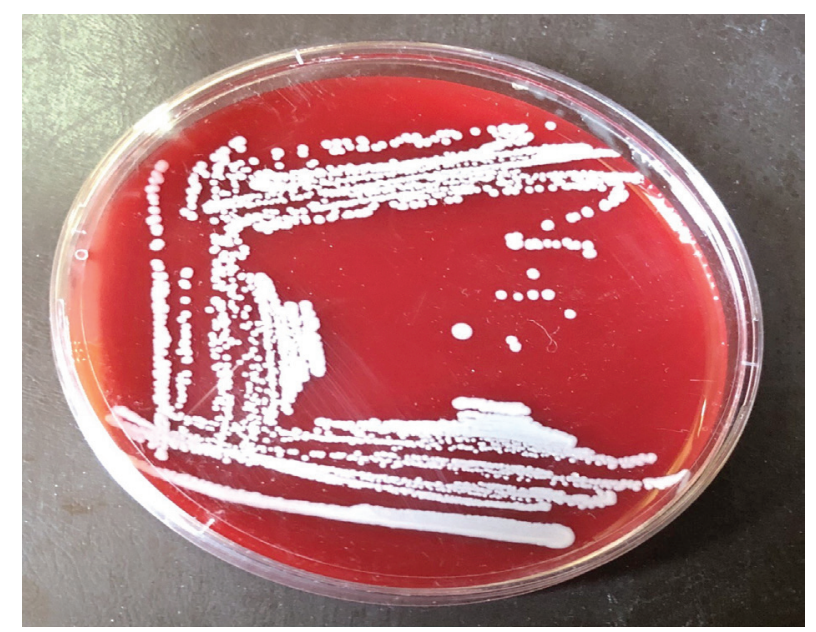

Figure 1: $S$. aureus colonies appeared yellowgray, round, smooth, raised, and some colonies surrounded by a halo or clear zone of $\beta$ -

\section{haemolysis.}

whereas colonies appear on mannitol salt agar surrounded by a yellow halo, this indicated that $S$. aureus have the ability to ferment mannitol sugar to produce acid in the medium, which leads to 
decrease $\mathrm{pH}$ and alter the phenol red color from red to yellow. Mannitol salt media contains mannitol carbohydrate that can be used by bacteria as a carbon source, high salt concentration reached to $(7.5 \%)$ $\mathrm{NaCl}$, and phenol red as a $\mathrm{pH}$ indicator, due to the high salt concentration, this media serves to inhibit the growth of the majority of bacterial species, except staphylococci, these results came in accordance to the characteristics mentioned by Mahon et al. ${ }^{[12]}$.

\section{Antibiotics dises}

(Methicillin, Ampicillin, Amoxillin, Augmentin, Piperacillin, Cloxacillin, Vancomycin, Rifampin, Amikacin, Ciprofloxacin, Tobramycin) by disc diffusion method according to the Kirby-Bauer [13] (Table 3).

Table 3: Antibiotic susceptibility test result of $S$. aureus

\begin{tabular}{|c|c|c|c|c|c|}
\hline Antibiotic & Resistance No (\%) & $\begin{array}{c}\text { Intermediate } \\
\text { No (\%) }\end{array}$ & $\begin{array}{c}\text { Sensitive } \\
\text { No (\%) }\end{array}$ & Total & P-value \\
\hline Methicillin & $45(90 \%)$ & $5(10 \%)$ & $0(0 \%)$ & 50 & $0.0001 * *$ \\
\hline Ampicillin & $45(90 \%)$ & $5(10.0 \%)$ & $0(0 \%)$ & 50 & $0.0001 * *$ \\
\hline Amoxillin & $42(84.0 \%)$ & $8(16 \%)$ & $0(0 \%)$ & 50 & $0.0001 * *$ \\
\hline Augmentin & $39(78.0 \%)$ & $9(18.0 \%)$ & $2(4.0 \%)$ & 50 & $0.0001 * *$ \\
\hline Piperacillin & $35(70.0 \%)$ & $7(14.0 \%)$ & $8(16.0 \%)$ & 50 & $0.0001 * *$ \\
\hline Cloxacillin & $33(66.0 \%)$ & $7(14.0 \%)$ & $10(20.0 \%)$ & 50 & $0.0001 * *$ \\
\hline Rifampin & $22(44.0 \%)$ & $2(4.0 \%)$ & $26(52.0 \%)$ & 50 & $0.0001 * *$ \\
\hline Vancomycin & $18(36.0 \%)$ & $2(4.0 \%)$ & $30(60.0 \%)$ & 50 & $0.0001 * *$ \\
\hline Ciprofloxacin & $2(4.0 \%)$ & $3(6.0 \%)$ & $45(90.0 \%)$ & 50 & $0.0001 * *$ \\
\hline Amikacin & $0(0 \%)$ & $0(0 \%)$ & $50(100.0 \%)$ & 50 & $0.0001 * *$ \\
\hline Tobramycin & $0(0 \%)$ & $0(0 \%)$ & $50(100.0 \%)$ & 50 & $0.0001 * *$ \\
\hline \multicolumn{6}{|c|}{$* *(\mathrm{P} \leq 0.01)$} \\
\hline
\end{tabular}


The present study demonstrates that most S. aureus isolates have high percentage of resistance to Methicillin and Ampicillin, Therefore the isolates considered as MRSA (Methicillin and Ampicillin resistant S. aureus)

Rapid conventional confirmation of $S$. aureus identification was performed using Vitek2 system its fluorogenic and turbidimetric method. Detection $S$. aureus isolates in current study gave positive results, where $50(100 \%)$ of suspected $S$. aureus were confirmed as $S$. aureus, these results was consistent with reference by Cheebrough ${ }^{[13,14]}$.
The genomic DNA of $S$. aurous isolates were extracted by a commercial wizard genomic DNA purification kit, concentration and purity of the DNA were carried out by using Nanodrop. The extracted DNA was analyzed by gel electrophoresis using (2\%) agarose gel and DNA Red safe dye, at voltage (70) for (30) minutes. The result showed that purity was good and ranged from (1.8-1.85) and the concentration ranged from $(10-12 \mathrm{ng} / \mu \mathrm{l})$, besides the results of gel electrophoresis showed sharp bands of chromosomal DNA as shown in figure $(7 a, b, c)$.

A

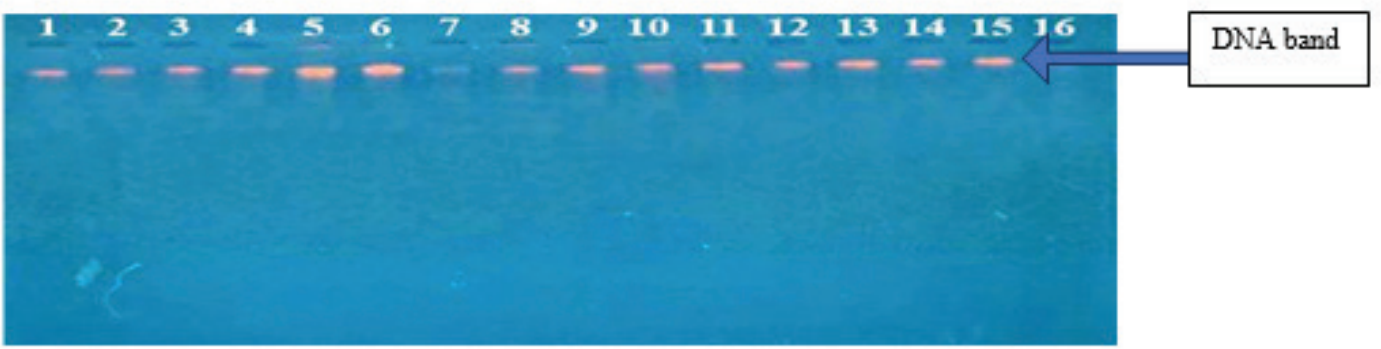

B

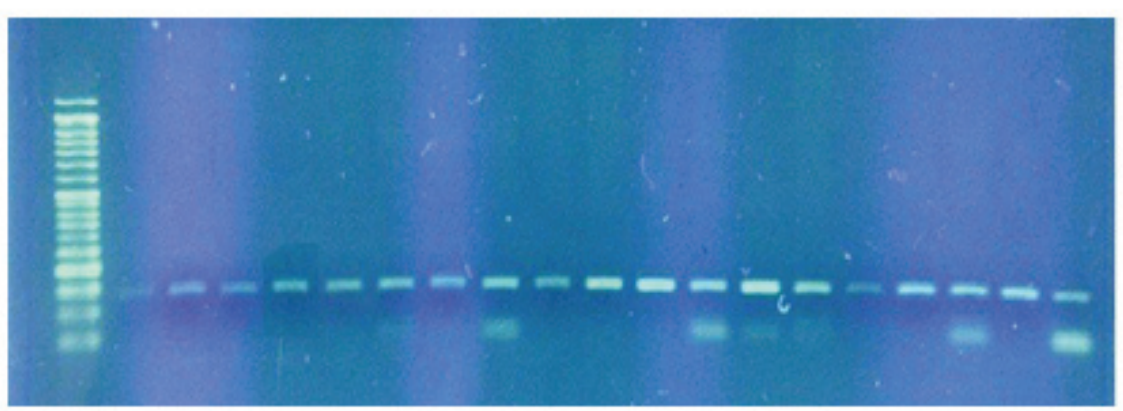

C

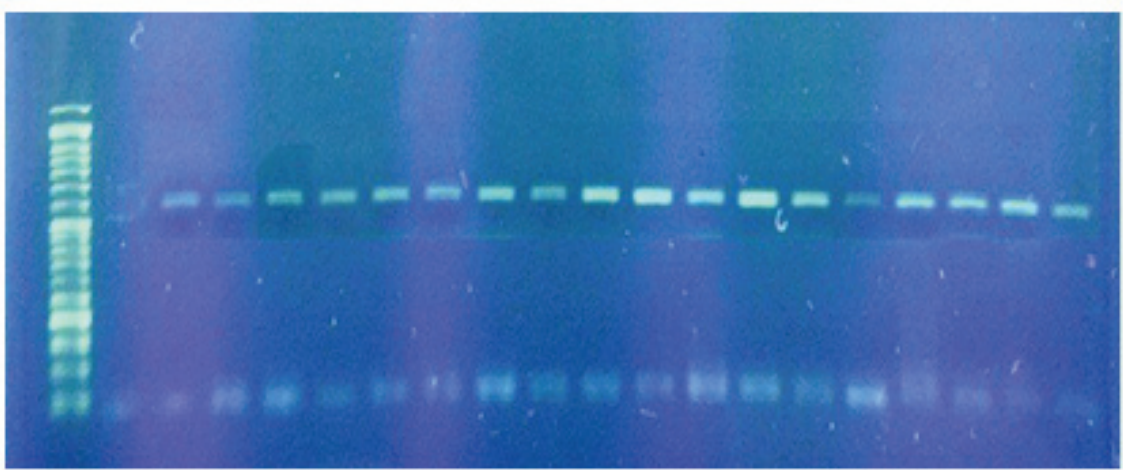

Figure 2: 
a- Gel electrophoresis of genomic DNA in (2\%) agarose gel at (70) volt for (30) $\mathrm{min}$,

b- Detection of PCR product of $16 \mathrm{~S} R \mathrm{NA}$ gene (164 bp).

c- Detection of PCR product of femA gene (647 bp).

The PCR analysis was employed in this study for amplified essential gene regions ( $16 \mathrm{Sr} R N A$ and $\mathrm{fem} A$ ) on $(1.5 \%)$ agarose gel at 70 volts for 45 minute the result of $16 S$ RNA showed an amplified fragment of (164 bp) as a clear band by electrophoresis as shown in figure (7b). Whereas, the result of amplification fem $A$ gene was appeared as a clear band of (647 bp) as a clear band by electrophoresis as shown in figure (7c). Results of current figure showed that 50 of sample with percentage $100 \%$ were positive for $16 \operatorname{SrRNA}$ gene, while 45 with percentage $90 \%$ were positive for $\operatorname{fem} A$ gene

\section{Discussion}

Bacterialculture,microbiologicalcharacterization, biochemical tests and are the mainstay of $S$. aureus diagnosis, yet it is only positive in approximately 40 $60 \%$ of presumptive cases. Various factors contribute to this lack of sensitivity as handling and preserving the sample, validity of used materials, transferring samples, efficiency of laboratory workers, most of the tests are based on experience and personal evaluation ${ }^{[15]}$. A very common reason for impaired sensitivity is pretreatment with antimicrobials prior to attending a hospital or healthcare facility. Therefore, there is an urgent need to establish reliable high-resolution diagnosis methods for $S$. aureus. The strategy to reduce the time to $S$. aureus diagnosis and increase the sensitivity by a combination of classical and molecular methods [16]. The advantage of such a method is an increase in the speed of a positive confirmatory diagnosis, and to produce a greater level of sensitivity than that of culturing alone.
In present study, (215) tonsils swab collected from individuals susceptible with tonsillitis; (195) samples were positive for bacterial growth. The results of classical diagnosis methods showed that (50) out of $195(90.69 \%)$ were S. aureus while molecular diagnoses showed that 45 isolates out of 50 $(100 \%)$ suspected $S$. aureus isolates which diagnosis via classical methods, little number of bacteria can fail to be detected using culture diagnosis, particularly if the patient has been treated with antibiotics before testing, but with PCR protocol it was able to detect DNA of $S$. aureus in tonsillitis patients even thought in low level.

According to the results of Amoxillin and Augmentin, the interpretation of this result may be due to that these antibiotics are widespread use for treatment of Staphylococcal infections in Najaf province and in whole of Iraq, what explains the resistance of isolates to these antibiotics. The detection of MRSA is an important mater for patients care and infection control committee. Globally many previous studies agreed with present study as search of Thomas ${ }^{[17]}$ found that more than (90\%) of $S$. aureus was MRSA of the core culture of tonsils in patients with recurrent and chronic tonsillitis. Brook et al. ${ }^{[18]}$, found MRSA at the period (2004-2006) from acute and chronic sinusitis. But the results of present study disagree with Mathew, ${ }^{[9]}$ found $(33.3 \%)$ of $S$. aureus from core and surface of infected tonsils were MRSA, the 16SrRNA gene are responsible for diagnosis Staphylococcus genus, so this study employed PCR to detect $16 \operatorname{Sr} R N A$ gene for identifying and confirmed all the staphylococcal isolates as $S$. aureus. Several studies have used this method for more rapidly and reliably. The results of current study agree with result of a same study in Iran reported by ${ }^{[18]}$ who noticed that amplification of $16 \mathrm{~s}$ rRNA confirmed all the (126) staphylococcal isolates that involved in the study as $S$. aureus. Several studies have reported the use of $f e m A$ as marker for detection of methicillin resistance. 
However, femA alone does not solely confer the methicillin resistance. Studies have shown that fem (factors essential for methicillin resistance) or the auxiliary genes like fem $\mathrm{A} / \mathrm{B} / \mathrm{X}$ in addition to mec $\mathrm{A}$ are also important in the expression of methicillin resistanc ${ }^{[11]}$.

Although the detection of femA gene remains the gold standard for detecting methicillin resistance, its detection alone does not confirm the presence of $S$. aureus and there is no consensus on the molecular target that could be used to confirm the $S$. aureus species. Constitutively expressed genes such as fem $\mathrm{A}$ and $f e m B$ are being used as molecular targets for the identification of $S$. aureus species. Therefore, the current study relied on a combination of two genes (16SrRNA and femA) to diagnose S. aureus. During screening for methicillin resistance markers in clinical isolates, it was observed all tested isolates were positive for the genus specific fem A (647bp). The results of recent study agreed with ${ }^{[2]}$ who found all of the (176) samples which tested contained the fem $A$ gene. However, the results of current study disagreed with [3] when found femA PCR out of the $54(29.6 \%)$ isolates in the detection of $S$. aureus where it showed that polymorphisms in femA gene sequences are present in MRSA isolates in India and requires further investigations such as sequencing to characterizes the genome in general and $f e m A$ in particular.

\section{Conclusion}

It can be concluded that the molecular methods are more sensitive in diagnoses of $S$. aureus than classical tests in case of tonsillitis in Iraqi sample.

\section{Conflict of Interest: None}

Funding: Self

Ethical Clearance: Not required

\section{References}

1. O'Handley JG, Tobin EJ, Shah AR. Otorhinolaryngology. Textbook of family medicine. 2012:300.

2. Brodsky L. Modern assessment of tonsils and adenoids. Pediatric Clinics of North America. 1989 Dec 1;36(6):1551-69.

3. Janda JM, Abbott SL. 16S rRNA gene sequencing for bacterial identification in the diagnostic laboratory: pluses, perils, and pitfalls. Journal of clinical microbiology. 2007 Sep 1;45(9):2761-4.

4. Maidhof H, Reinicke B, Blümel P, Berger-Bächi B, Labischinski H. femA, which encodes a factor essential for expression of methicillin resistance, affects glycine content of peptidoglycan in methicillin-resistant and methicillin-susceptible Staphylococcus aureus strains. Journal of bacteriology. 1991 Jun 1;173(11):3507-13.

5. Atlas, R.; Brown, A. and Parks, L. (1995). Laboratory Manual of Experimental Microbiology. 1St ed. Mosby. USA.

6. Sambrook J, Russell DW. Molecular cloning a laboratory manual. 434 Cold spring Harbor. New York. 2001;435.

7. Al-musawi MH, Al-Rubaye MT, Hosseini M. Culture and Molecular Detection of Staphylococcus aureus in Dairy Products of Ahwaz. Al-Mustansiriyah Journal for Pharmaceutical Sciences. 2014;14(2):103-7.

8. Sagaidak S, Taibi A, Wen B, Comelli EM. Development of a real-time PCR assay for quantification of Citrobacter rodentium. Journal of microbiological methods. 2016 Jul 1; 126:767.

9. Barzani KK, Turkey AM, Abed JJ. Comparison Study of mecA Gene-Based PCR With Phenotypic Methods For Detecting Biofilm Forming Methicillin Resistant Staphylococcus aureus 
Isolates and Comparison of mecA With femA, femB, and mec Genes. Journal of university of Anbar for Pure science. 2017;11(1):1-8.

10. SAS. (2012). Statistical Analysis System, User's Guide. Statistical. th ed Version 9.1. SAS. Inst. Inc. Cary. N.C. USA.

11. Leboffe MJ, Pierce BE. A photographic atlas for the microbiology laboratory. Morton Publishing Company; 2012.

12. Mahon CR, Lehman DC. George ManuselisTextbook of Diagnostic Microbiology.

13. Bauer, A.; Perry, D. and Kirby, W. (1959). Single disc antibiotic sensitivity testing of Staphylococci. A.M.A. Arch. Intern. Med. 104:208-216.
14. Cheesbrough M. District laboratory practice in tropical countries, part 2. Cambridge university press; 2006 Mar 2.

15. Bagnoli F, Rappuoli R, Grandi G, editors. Staphylococcus aureus: microbiology, pathology, immunology, therapy and prophylaxis. Springer; 2018 Jan 24.

16. Thomas dr. comparative study of the core culture of the tonsils in patients having recurrent chronic tonsillitis vs tonsils with obstructive symptoms in a tertiary care institute.

17. Brook, I. Diagnosis and management of pharyngotonsillitis. Israeli Journal of Emergency Medicine (2008). 8 (2): 26-34 